\title{
An Introduction to the Tools of Cinematic Adaptation
}

\author{
Dr. Devesh Kumar Sharma ${ }^{1}$ \\ Assistant Professor \\ Amity University, Noida \\ Ms. Ulka Tewari ${ }^{2}$ \\ Assistant Professor \\ Amity University, Noida
}

\section{Abstract:}

Our world is often referred to as the "world's imagination", its virtual world, and the illusion of the real world. Writers gave wings to their imagination and created a series of imaginations in the form of writing known as "literature". Literature, a written masterpiece does not reach a wider audience due to illiteracy, but Cinema has not left any corner of the world untouched with its magic. Though there are many forms of literature, which are divided into four main categoriesproses, drama, poetry, and fiction but the transmutation of literature is still a challenge. This research will present a compact understanding of Cinematic Adaptation and the Tools used in the process of transmutation of 'Script to Screen'.

Keywords: Cinematic Tools, Cinematic Adaptation, Semiotic Translation, Fidelity Discourse.

"Cinema is the most beautiful fraud in the world" opines Jean-Luc Godard. Any attempt made in this direction is a further discovery of it. Therefore, cinema is a conceivable art form and it is a valuable innovation in itself. Literature is the mirror of society that is well known but that mirror remains a constrained one due to the literacy issue and the varied range of literary interests that people share. The masses, or the non-literary crowd, are never able to witness the literary picture. Cinema, on the other hand, is a tool that has mass appeal. So, when these two forms of art blend, they make a masterpiece. There was a time when Aristotle and Plato proclaimed speech superior to writing as it was considered an impure exercise. Then there was a time when the drama was called a 'lowly act'. So, the games of denouncements and upgrades are a way of life. In the contemporary world, cinema has reached its advancement and several bestsellers have been transmuted into blockbusters. The researchers and analysts of Cinema and Cinematic adaptations do need to know the tools of cinematic adaptation for the betterment of adaptation theories. Following are the tools of cinematic adaptation: 


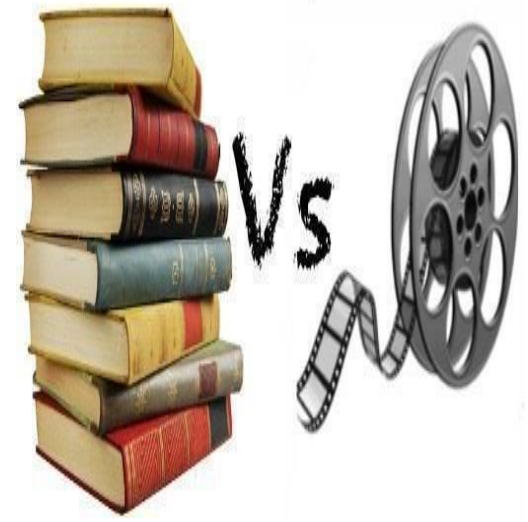

\subsubsection{Medium Description}

Being a visual medium, the film employs a multiplicity of techniques, but its greatest impact upon the novel is perhaps this visual aspect. The predominance of the visual in the fiction of these modernist writers manifests itself in two different manners. On one hand, the emphasis of the novelist is away from the object and towards the eye of the observer, a mode usually practiced by stream-ofconsciousness writers. On the other hand, there are direct occasions when the focus is more on the object as something else and therefore closer to the cinematographic form.

In his works, he uses verbal descriptions as a filmmaker uses the lens of his camera to select, highlight, distort, and enhance - in short, to create a visualized world that is both recognizable and is yet more vivid, intense, and dramatically charged than actuality. A good film director is likewise sensitive to the artistic use of the camera and often creates unforgettable scenes in his films. Like Joyce and Conrad, this manner of vision transports the viewer farther away from the seen object - without losing sight of it and therefore closer to the subject itself. Erasing the gulf between the object and the eye of the subject, the observer often stands dumb before the visual experience. This is precisely how the 'eye' of the camera also functions.

\subsubsection{Point of View}

Point of view in fiction determines the relationship between the narrative material and the narrator through whose eyes the events of a story are viewed. In literature, there are four basic types of point of view namely: the first person, the omniscient, the third person, and the objective. It has been seen that the 'objective' or 'impersonal' mode is naturally superior to any other form that allows for a direct appearance by the author or his reliable spokesman. In the movies, on the other hand, point of view tends to be less vigorous than in fiction because it gives the director the freedom to adjust his camera lens according to his will. Here, like an eye, the camera functions especially for a special purpose; seeing what the spectator could see if he were himself present at the event being photographed. Moreover, whenever the director desires, he can focus his camera upon subjective details and reject what is not essential. Unlike fiction, the film works by directly showing the fictional world to the spectator being 'seen' without the mediation of the narration. All that is seen in a film - the movements and gestures, the visual material selected to represent concepts, the variations and gradations in the lighting, and the performances of the actors are photographed by a motion picture. 
International Journal of Trends in English Language and Literature (IJTELL) An International Peer-Reviewed English Journal; Volume-2, Issue-3; 2021 $\underline{\text { www.ijtell.com }}$ Impact Factor: 5.144(SJIF)

ISSN: $2582-8487$

Norman Friedman writes in Point of View in Fiction: The Development of a Critical Concept that "narrators can be distinguished based on their angle on the narrative (above, center, front, shifting, and periphery) and by the way, they situate the reader at some distance from the story. Interestingly enough, even the term he uses to designate the narrator's relationship to the story, "point of view," is an optical metaphor and its visual consciousness manifests itself in the varied examples of literary equivalents of the cinematic 'long shots', 'close-ups', and 'mid shots, and so on. In movies, the reader fuses with the lens and views it from that point of view. Each time the director moves his camera either within a shot or between shots - a new point-of-view is offered from which to evaluate the scene. He can concentrate on a single reaction (close-up) or the simultaneous reactions of social characters (long shot) in modern fiction. The novelist uses space as a filmmaker does, and his pen becomes the camera- moving, describing, and recording cinematically. The visual technique he uses can be analysed in cinematic terms: 'long-shot, 'close-up', 'wide-angle', 'zoom', 'freezeframe, 'soft-focus, 'dissolve', 'slow-motion', 'dolly shots, 'panoramic shots', and so on. Terms like close-up, medium shot, long shot refer to the distance of the camera from the object or to the choice of a particular section of that object or person to be represented. ".

\subsubsection{Montage}

Montage provides an important starting point for discussing and evaluating what writers have seen as correspondences between fictional and cinematic space.
Generally, 'montage' has two distinct though allied meanings. The first involves the stylistic system of film, the way one shot is joined to another. Technically, 'montage' is the French term for editing or cutting; its sense is that shot $\mathrm{A}$ is "mounted" next to shot B, etc. Ezra Pound's definition of the structure of the ideogram recognized montage as its central aesthetic principle. In the sense that Sergei Eisenstein uses the term, "dialectical montage" it means simply that shot A Cojedes with shot B to generate C. Montage enables the film director to endow his shots with a meaning beyond the scope of their apparent ideological content. It enables him to take the dead photographs from which a film is composed and infuse life into them. Thus montage, literally the act of mounting a film's shots to endow them with significance, depth, and vitality becomes the very essence of the filmmaking technique. This close relationship between the novel and the film in the use of the montage technique is evident in the novels of the stream-of-consciousness writers especially those of James Joyce and Virginia Woolf.

\subsubsection{Treatment of Time}

Understanding how time is treated in cinema leads to a common apprehension of the use of the time of the novelist in their fiction. With the help of camera devices, the unchanging nature of physical time can be slowed down, speeded up, telescoped, or stretched out to remarkable lengths or even at moments 'frozen'. The chronological handling of time by the modern novelists, therefore, finds suitable parallels with techniques like 'flash-back, 
'slow-motion', 'stasis', 'ellipsis', 'dissolve' and 'jump-cut. Prose fiction narrative consists of actions, agents, temporal and causal relationships. In the film, spatial context is crucial and a much more significant formative element than the novel. Here, a shot depicts action and this action must take place somewhere in a physical space. The action must also take place at the same time. Because the action or ideological content of a shot must take place in a physical space, it sometimes refers to the ideological relationships between shots of a film as their spatial relationships, though in actual practice the relationships of time and space can never be separated. In the real world, the world as distinguished from the cinematic, there are certain laws of time and space which any person can verify from his own experience - first, the observation is that in the real world a given area of space is always the same size and hence one cannot alter its dimensions, second, in the real world time cannot be made longer or shorter than it is. Third, one cannot be in two different places at the same time; and fourth, in the real world time cannot be made to go backward. All these observations can be termed the laws of reel space and time. In the film, it is possible to expand and contract time and space. The technique of balancing parallel images is central to the film's structure and is most consistently devoted to demonstrating the relationship between the past and present.

Both novels and films are time arts; while the formative principle in a novel is time, the formative principle in a film is space. The novel renders the illusion of space by going from point to point in time; the film renders its time by going from point to point in space.

The modernist writers use the flashback technique quite overtly. Their deep sense that reality is described fully only in the paralleling of the external flow of events and internal flow of consciousness justifies his distinctive experiments with the form. Since the past is an important factor in understanding their fiction, the flashbacks are not simply functional- they are thematically necessary and consequently justify the montage structure of their works. Closely connected with the method of 'flashback' are the use of dreams and the stream-of-consciousness technique. In the film, inserting a dream sequence within a narrative is the easiest method of manipulating time.

\subsubsection{Motion v/s Stasis}

The aesthetics of cinema can be summarised in one word: 'movement'. Motion in a film can be achieved in several ways. First, the camera can show the same moving action from several points of view. The second way by which a film achieves motion is by the movement of the camera itself. Another instance is using the camera lens. In this method, an illusion of motion is created through the change in the camera lens. The 'zoom' lens and the 'close-up' lens which change the focal length are very effective for suggesting motion. In the film, the director can not only create the impression of movement, but it's very sensation by control over the rhythmic beat. 
International Journal of Trends in English Language and Literature (IJTELL) An International Peer-Reviewed English Journal; Volume-2, Issue-3; 2021 $\underline{\text { www.ijtell.com }}$ Impact Factor: 5.144(SJIF)

ISSN: $2582-8487$

\subsubsection{Language and Style}

In her erudite book Double Exposure: Fiction into Film, Joy Could Boyum differentiates between the language of fiction and the language of the film arguing that "style in a film must be constructed out of totally different elements: pictorial decor and composition; camera movement and editing; transitional devices and lighting, score and sound effects, and so on". Building her case on assumptions, she categorically states that. "Literary and cinematic languages are markedly different in their emotional and intellectual charge."

\subsubsection{Sound v/s Silence}

In a film, the use of sound is very significant especially in the way it relates to the visuals be it synchronous, asynchronous, contrapuntal, or ironic. Similarly, silence in cinema is used to heighten fear, increase tension, or build suspense. Since sound in a film is essentially an element in the composition of the shot, it adds to the significance of other elements in the shot - namely, visual material, movements and gestures, lighting, and camera angles. When sound is used to convey specific meaning to the spectator i.e. to express ideological content, it blends with all the other elements in the composition of the shot that serve the same function, so that the sound and the visual image form a perfect unity. Like other cinematic devices, uses of sound and silence in the works of modern writers are significant too. The critic George Bluestone notes that sound can indicate past, present, and future relationships though he asserts that "sound is a secondary advantage which does not seriously threaten the primacy of the spatial image."

\subsubsection{Light}

The use of light, which is inherent in the photographic process, is an integral part of the filmmaking technique. It alters the external appearance of the things in the world and therefore the significance of light is overwhelming. Light is the essence of the aesthetic and chemical properties of a film, whereas light is only incidental to the description and symbolic possibilities of literature, though the symbolic possibility is shared with the film. As in the film, the novelists often use the variations in nuances and moods of his characters through the varied uses of light. As a part of the visual emphasis that has been mentioned earlier, the significance of light is noteworthy in the fiction of a few major novelists as well. Generally in a film, the director shifts and transposes the lighting tones in the various shots by variations in the mood of the film. Moreover, this transposition is in itself the instrument for the powerful expression of emotions in a film.

Film theorists, as well as literary critics, constantly dwell upon the interrelationship between the two art forms of literature and cinema. The controversy about their inter-connectedness is perhaps a hundred years old, beginning right from the days of cinematographic history. Ideally, the novel and the film should be regarded as independent entities, but several critics have harped upon the question of fidelity of the film with the text. According to the French critic, Jean Mitry, "a novel is a narrative that organizes itself into a world; a film is a 
world that organizes itself into a narrative" Mitry argues that the adaptation of a novel to film rests on the absurd assumption that there exists a content which can be transferred and transformed from one form of expression to another. But in art, the content does not exist apart from its form. Marie Seton, in her biography of Satyajit Ray specifically mentions this problem when she admits, "Books are not primarily written to be filmed, if they were, they would read like scenarios; if they were good scenarios, they would probably read badly as literature"

Since the birth of cinema, immortal creations of literature have inspired filmmakers towards achieving ever greater artistry in the search for visible expressiveness that can rival the power of words. Film's strength has always been the expression of emotion. Considering the 'novel versus film' debate with special focus on the problems of adaptation, it can therefore be unanimously accepted that as long as popular novels or literary masterpieces will be adapted on the screen, these problems will persist and critics will go on harping that the sanctity of the literary text has been destroyed.

\subsection{Semiotic Translation}

Semiotics is the study of how meaning is created and how it is transmitted. Its origin is in academic research on how signs and symbols (visual and verbal) produce meaning.

It is a way to look at the world, and a way to understand how the landscapes and cultures we live in unknowingly affect all of us.
For example, if the color of the traffic light is different, you know how to react automatically. We know this without thinking about it. However, this is established over a long period by cultural practice, and it is a sign that we learn from childhood, and it requires insensible cultural knowledge to understand its meaning.

By looking at this sign and interpreting it (or deciphering it), you can navigate the scenery of the city and society.

\subsubsection{Definition and Examples of Semiotics}

Semiotics is the study of symbols and signs to convey what is being spoken and what is not spoken. Common examples of semiotics include traffic signs, emoticons, and emoticons used in electronic communications, logos, and brands that international companies use to sell things, and "brand loyalty".

However, signs are always around us. Consider a pair of faucets in the bathroom or kitchen. In your kitchen, the left side is almost certainly a hot water faucet and the right side is cold. About 20 years ago, the tap also had letters that indicate the temperature of the water. In English, His hot, C is cold. However, in Spanish, it was $\mathrm{C}$ for hot (Caliente) and $\mathrm{F}$ for cold (frio). Modern faucets have no letter designation or are included in one tap. However, even with one tap, the content of the faucet sign is still inclined, or it turns to the left for hot water and to the right for cold. Information on how to avoid burns is a marker: you know which direction to lean. 
International Journal of Trends in English Language and Literature (IJTELL) An International Peer-Reviewed English Journal; Volume-2, Issue-3; 2021

\subsubsection{Practice and History}

Those who study or practice semiotics are known as semioticians. Saussure has defined symbols as movements, gestures, images, patterns, or events that convey meaning. Langue is defined as the language structure or grammar, and parole is defined as the actual choice made by the speaker to convey that information.

Semiotics is important to research in thinking about the evolution of human consciousness. The British philosopher John Locke (1632-1704) tied the progress of intelligence into three steps. The words began with the signs. In Locke's terms, the signs are binary. In other words, the symptoms are tied to a specific meaning.

Charles Sanders Peirce (18391914) pointed out that the sign only works if there is intelligence that can be learned from the experience. The meaning of the symbols, the interpreter, and the notion of Pierce's semiotics were triples. Modern semioticians look at the entire network of signs around us, signs and symbols that mean different things in different contexts, and even sound signs and symbols. Consider what the ambulance siren tells you while driving. "Everyone is in danger and can hurry there."

\subsubsection{Examples of Semiotics: Textual Signs}

Inter-textuality is a kind of subtle communication in that we write and say remember something that is shared among us. For example, saying "Luke ..." and imitating James Earl Jones's deep baritone may convey to the listener many images, sounds, and meanings of Star Wars. "You know the semiotics you are, Grasshopper" is a reference to both Master Yoda and Master Poe of the "Kung Fu" TV show of the 1970s: in fact, you are semiotic to Master Po. It can be argued.

Metaphors can act as a meaningful alternative to those familiar with the culture. They are so common that it doesn't matter if you read the Bible. "The Smoke" is a reference to smog, which used to be popular, and means London even if the smog is not so popular.

\subsubsection{Nonverbal Communication and Semiotics}

Many of the ways we communicate with each other are nonverbal, without words. Shrugging, curling eyes, waving, all these and more subtle and unsubtle body language memes convey information to others. Vocals are a type of non-verbal communication embedded in speech: the pitch, tone, rate, volume, and timbre of spoken language convey additional information about the underlying meaning of a group of words.

Personal space is also a kind of culture-specific semiotics. People who get too close to you in Western culture may be perceived as hostile to invasion, but in other cultures the dimension of personal space is different. Depending on the situation, you can calm, anger or anger angry or sad people simply by touching someone.

It is important to note that the transmutation of one art form from another also has some limitations and it is of utmost importance for the director to understand the emotions and background 
of authorial dominance and the same is to be applied while making a movie based on a text.

\subsection{The Fidelity Discourse}

Film theorists and literary critics are always based on the interplay between the two art forms, literature and films. The controversy about their interoperability began from the age of film history and is probably 100 years ago. Ideally, novels and films should be regarded as independent entities, but some critics have plagued the issue of text and film fidelity. According to the French critic Jean Mitry, "a novel is a story that brings itself into the world. A movie is a world that brings itself into a story." There is content that can be transferred and converted to another presentation format. But in art, content does not exist outside of its form. Marie Seton, in her Biography of Satyajit Ray, reads, "The book is not written to be primarily filmed, but read like a scenario."

\section{Conclusion:}

The critical analysis of the book should be based on various literary approaches such as a formalist approach to literary research, a structural approach, a feminist approach, a post-structural approach, and a postmodern approach. The film also needs to be analyzed based on the various parameters that apply to the film research described in this research. The script version is then compared with its screen version, and conclusions can be drawn based on the comparison. The purpose of this work is not to prove that a particular art form is superior to other art forms, but to conclude how the art forms presented to the audience in different arrangements may have different effects Gathering of the same audience. Both of these forms are individually great and should be respected within their domain, but it is also interesting to study how they overlap, interact and influence society. This is research has mentioned several tools to learn both for analysis/research and/or development of a cinematic adaptation.

\section{Bibliography}

Webliography

http://www.brainyquote.com/quote s/quote s/e/ezrapound106459.html Nov $25^{\text {th }}, 2020$

http://www.brainyquote.com/quote s/keyw ords/literature.htmlMay $25^{\text {th }}, 2021$ http://www.cartoonstock.com/direc tory/f/fi lm_adaptation.asp https://edtimes.in/books-vs-movies/ Dec $1^{\text {st }}, 2020$

https://www.koimoi.com/photos/photostories/list-of-hindi-films-basedon-novels/attachment/bollywoodfilms-based-on-novels-8/ March $13^{\text {th }}, 2021$.

\section{References}

Abramson, Ronald. "Structure and Meaning in the Cinema." Movies and Methods. edited by Nicholas Bill, vol. 2, Seagull, Calcutta: 1993.

Andrew, Dudley. J. Major Film Theories, OUP, 1996.

Arnheim, Rudolf. "Film as an Art." Film Theory and Criticism. edited by 
International Journal of Trends in English Language and Literature (IJTELL)

An International Peer-Reviewed English Journal; Volume-2, Issue-3; 2021

Gerald Mast and marshal Cohen, OUP, 1985.

Arnheim, Rudolf. "The Complete Film from Film as an Art." Film Theory and Criticism. edited by Gerald Mast and Marshal Cohen, OUP, 1985.

Balazs Bela. "Theory of the Film." Film Theory and Criticism. edited by Gerald Mast and marshal Cohen, OUP, 1985.

Barr, Charles. "Cinemascope, Before and After." Film Theory and Criticism. edited by Gerald Mast and Marshal Cohen, OUP, 1985.

Bazin, Andre. "The Evolution of the Western." Movies and Methods. edited by Nichols Bill. Seagull, Calcutta: 1993.

Beja, Morris. Film \& literature: an introduction, Longman, 1979.

Bluestone, George. Novels into film, Univ of California Press, 1968.

Boyum, Joy Gould. Double exposure: fiction into film, New American Library, 1985.

Cartmell, Deborah, and Imelda Whelehan. Adaptations: from text to screen, screen to text, Routledge, 2013. 